\title{
Non-indigenous grasses impede woody succession
}

\author{
Mark A. Davis*, Louise Bier, Ethan Bushelle, Chloe Diegel, Aleta Johnson and Brianna \\ Kujala \\ Department of Biology, Macalester College, Saint Paul, MN 55105, USA; *Author for correspondence \\ (e-mail: davis@macalester.edu; phone: +1-651-696-6102; fax: +1-651-696-6443)
}

Received 14 January 2004; accepted in revised form 20 September 2004

Key words: Old fields, Quercus, Resource availability, Succession, Woody seedling establishment

\begin{abstract}
With the proliferation of old fields and the decline of native grasslands in North America, non-indigenous grasses, which tend to colonize and dominate North American old fields, have become progressively more abundant. These new grasses can differ from native grasses in a number of ways, including root and shoot morphology (e.g., density of root mat, height of shoots), growth phenology (e.g., cool season vs. warm season growth), and plant-soil-water relations due to differences in photosynthetic physiology $\left(\mathrm{C}_{3}\right.$ vs. $\left.\mathrm{C}_{4}\right)$. Woody plants have been slow to colonize some old fields in the prairie-forest border area of North America and it is hypothesized that non-indigenous grasses may be contributing to the poor establishment success of woody plants in this region, possibly through more intense competition for resources. To test this hypothesis, a multi-factorial field experiment was conducted in which water, nitrogen, and grass functional group (non-indigenous $\mathrm{C}_{3}$ and native $\mathrm{C}_{4}$ species) were manipulated in a study of survival of oak seedlings. The grass type variously affected some of the different growth measurements, however, the effects of grass type on seedling growth were small compared to the effects on seedling survival. The results showed that when grown under dry conditions, seedlings growing in non-indigenous grasses experienced up to a $50 \%$ reduction in survival compared to those growing in native grasses under the same conditions. Analyses of root and shoot competition showed that the cause for the reduced survival in the non-indigenous grasses was due primarily to underground processes. The findings confirmed our initial hypothesis that nonindigenous grasses are likely contributing to the poor establishment success of woody plants in these old fields. However, the explanation for the reduced oak seedling survival in non-indigenous grasses does not appear to be due to reduced resource availability since soil water levels did not differ between nonindigenous and native grass plots and other resource levels measured (light, $\mathrm{NO}_{3}$, and $\mathrm{NH}_{4}$ ) were higher in non-indigenous grass plots under dry conditions. An alternative explanation is that the non-indigenous grasses modify the soil environment in ways that, under dry conditions, are deleterious to emerging oak seedlings. Since current climate projections for the upper Midwest are for hotter and drier summers, the results suggest that the resistance of these old fields to oak encroachment will likely increase in the future.
\end{abstract}

\section{Introduction}

Although secondary succession and the introduction of new species into a region both involve colonization and establishment processes, and although both are often initiated by disturbance, research efforts in invasion ecology and succession ecology have generally not been well integrated 
(Davis et al. 2001; but see Williams 1983; 1992; Rejmánek 1989; Bastl et al. 1997). In addition to sharing similar processes and dynamics, the processes of succession and species introductions may directly interact and affect one another. For example, if non-indigenous species significantly affect key ecosystem attributes or processes (Hobbs and Huenneke 1992; D'Antonio and Vitousek 1992; Vitousek et al. 1997; Christian and Wilson 1999), they may affect historical successional patterns and dynamics.

In North American grasslands, shrublands, and savannas, tree establishment in grassland vegetation is a successional process and occurs in several contexts. It occurs in historical oak savanna environments where, unless checked by fire, it initiates the conversion of the savannas into woodlands and forests (Curtis 1959; Wovcha et al. 1995; Davis et al. 1997). In old fields and pastures, tree establishment is part of the successional process that eventually converts the fields into woody environments (de Steven 1991; Inouye et al. 1994; Ganade and Brown 2002). The rate of woody encroachment into these environments has changed during the past century, increasing in some regions (Archer 1989; Van Auken 2000) and decreasing in others (del Moral 1985; Goldberg and Gross 1988; Inouye et al. 1994; Lawson et al. 1999). These changes in woody encroachment have been variously attributed to changes in fire frequency, grazing and browsing patterns, dispersal limitation, and resource availability (Archer 1989; Wilson 1993; Inouye et al. 1994; Weltzin et al. 1997; Davis et al. 1999; Van Auken 2000; Kochy and Wilson 2001).

In the prairie-forest border, old fields on coarsegrained soils are experiencing very low rates of tree establishment (Inouye et al. 1994; Lawson et al. 1999), with some fields many decades old still exhibiting little oak encroachment despite being surrounded by oak woodland and forest. In contrast, oaks regularly establish in the grassland openings of adjacent native savannas and woodlands (Peterson and Reich 2001) and in native grasslands further south (Danner and Knapp 2003). The old fields and native environments differ in their dominant grass species, with the native savannas and grasslands dominated by native warm-season grasses and the old fields normally dominated by introduced European cool season grasses. Grass effects on woody plants can vary depending on the grass species involved (Gordon et al. 1989; Rice et al. 1993) and some non-indigenous grasses have been found to alter ecosystem properties (Christian and Wilson 1999). Since non-indigenous $C_{3}$ and native $C_{4}$ grasses differ in their photosynthetic pathways and wateruse efficiency, we hypothesized that the nonindigenous grasses may be depleting soil water levels resulting in reduced oak seedling growth and survival. The purpose of this study was to test the hypothesis that non-indigenous grasses are contributing to the slow encroachment of trees in the old fields, and if so, that the non-indigenous grasses are impeding woody succession through the reduction of resource availability, particularly water.

\section{Materials and methods}

\section{Study site}

The study was conducted at Cedar Creek Natural History Area (CCNHA), Bethel, MN (45 $24^{\prime} \mathrm{N}$, $\left.93^{\circ} 12^{\prime} \mathrm{W}\right)$. CCNHA, a Long Term Ecological Research site, is situated on the Anoka Sandplain, a glacial outwash area that is characterized by coarse textured soils low in nitrogen (Grigal et al. 1974). This area is located in the transition zone between the central grasslands and the eastern deciduous forest of North America. Prior to settlement by Europeans, dry oak savanna and barrens were the dominant vegetation types, with bur oak (Quercus macrocarpa Michx.) and northern pin oak (Q. ellipsoidalis E. J. Hill), being the two dominant tree species (Wovcha et al. 1995). Today, upland, herbaceous dominated communities at CCNHA include old fields and natural openings in remnant oak savanna/woodland habitat. Dominant grasses in old fields are $\mathrm{C}_{3}$ species: Agropyron repens L., Bromus inermis L., and Poa pratensis L. Dominant grasses in Cedar Creek savannas are $\mathrm{C}_{4}$ species: Andropogon gerardii Vitm., Schizachyrium scoparium Michx., and Sorghastrum nutans L. (nomenclature: Barkley 1986).

Although east-central Minnesota is not considered a semi-arid environment based on climate (mean precipitation during the summer months is $32.4 \mathrm{~cm}$ ), little summer precipitation is retained for long in the sandy soils, and the vegetation of the Anoka Sandplain frequently experiences drought 
conditions. The study was conducted in a 35-yearold field, dominated by the old field grasses listed above.

\section{Site and plot preparation}

A multi-factorial field experiment was undertaken in which water input, nitrogen input, and grass group (native $\mathrm{C}_{4}$ and non-indigenous $\mathrm{C}_{3}$ species) were manipulated. A split-plot design was used, with the water treatment applied at the whole plot level and the nitrogen and grass treatments applied at the subplot level. The experimental design, which also included weeded subplots (no grass at al), permitted the quantification of the effects of root and shoot competition by grasses on oak seedling growth and survival along the waternitrogen gradient.

The site was prepared during spring 1999 by burning the field, then tilling the area and fumigating the soil with methyl bromide. Methyl bromide, which kills vegetation and seeds in the soil, and sterilizes the soil (http://www.epa.gov/ozone/ $\mathrm{mbr} / \mathrm{qa} . \mathrm{html}$ ) was applied to eliminate any legacy effect from the old-field $\mathrm{C}_{3}$ grasses, e.g., involving mychorrizae or other aspects of the microbial community. In early summer 1999 , plots were laid out and seeded with either native $\mathrm{C}_{4}$ (Andropogon gerardii, Schizachyrium scoparium, Sorghastrum nutans) or non-indigenous $\mathrm{C}_{3}$ grasses (Bromus inermis, Poa pratensis, Phleum pratense) in accordance with the experimental design described below. Plots were watered throughout summer 1999 to promote germination and growth of the grasses, and plots were allowed to mature during 2000 before acorns were introduced to the plots in fall 2000. The grass biomass recorded in the study plots in August, 2001 was comparable to, or slightly higher than, that recorded in long-established old field and savanna habitats at Cedar Creek (Tilman 1987; Davis et al. 1999).

Known herbivores of oak seedlings at Cedar Creek, white-tailed deer, Odocoileus virginianus, and pocket gophers, Geomys bursarius (Inouye et al. 1994), were excluded from the study site via fencing (deer) and trapping (gophers). Although herbivory by small rodents is an important source of tree seedling mortality in some old field systems (Myster and McCarthy 1989; Gill and Marks 1991), a previous study (Davis et al. 1999) showed that herbivory on oak seedlings by small rodents was inconsequential in the study field.

\section{Experimental design and plot layout}

The experiment combined a water gradient (three levels - dry, medium, wet), nitrogen availability (two levels - ambient, nitrogen added), and grass treatment (non-indigenous $\mathrm{C}_{3}$, native $\mathrm{C}_{4}$, and no grass) in a split-plot design that permitted the independent quantification of root and shoot effects of the grasses on oak seedling survival and growth in each of the above combinations. The experiment consisted of 24 whole plots $(2.75 \times 23.75 \mathrm{~m})$, each plot containing a row of 14 subplots $(1 \times 2 \mathrm{~m}$ with $0.75 \mathrm{~m}$ spacing between subplots). Thirty centimeter aluminum flashing was inserted into the soil between subplots to minimize root interactions between subplots. The rows of subplots were oriented in an east-west direction and this eliminated shoot interactions (e.g., shading) between subplots. Each subplot was surrounded by a $0.375 \mathrm{~m}$ buffer zone and treatments (water, nitrogen, grass functional group) were applied to the subplots and their buffer zones. The whole plots were laid out in three parallel rows with eight whole plots per row. Four meter separated whole plots within a row and rows were $8 \mathrm{~m}$ apart. The design included eight blocks at the whole plot level, each block consisting of three adjacent whole plots, one from each row. Each of the three water treatments (dry, medium, wet) was applied to one randomly selected whole plot within each block.

In order to distinguish between grass root and shoot effects on the oak seedlings, the seedlings were grown in four different treatments: root competition only, shoot competition only, both root and shoot competition, neither root nor shoot competition (the weeded subplots). A full factorial combination including the competition treatments yields a total of 16 combinations for each plot ( 2 nitrogen $\times 2$ grass functional groups $\times 4$ competition treatments). However, since the fourth root-shoot competition combination stated above (neither root nor shoot competition) is redundant for both grass functional groups in both nitrogen levels, only two, rather than four combinations are needed to produce the no root and no shoot competition combination for both grass functional groups. This yields the 14 combinations of 
nitrogen, grass functional group, and competition type for each plot. These combinations were randomly assigned to the 14 subplots in each whole plot. In total, the experiment consisted of 336 subplots $(14$ per whole plot $\times$ three whole plots per replicate $\times$ eight replicates).

\section{Competition treatments and acorn planting}

In each subplot, four root exclusion tubes $(10 \mathrm{~cm}$ diameter, $30 \mathrm{~cm}$ long) were pounded into the soil prior to the seeding of the subplots with grasses. Although grass roots extend deeper than $30 \mathrm{~cm}$, the majority of grass roots are normally found within the top $30 \mathrm{~cm}$ of soil (Jackson et al. 1996). In subplots designated as root competition only and those designated as root and shoot competition combined, grass was seeded into the tubes and throughout the rest of the subplot as well. In subplots designated as shoot competition only, grass was not seeded into the tubes, but grass was seeded into the rest of the subplot in order to provide shoot competition (shade). In subplots designated to have neither root nor shoot competition, no grass was seeded into the tubes or any part of the subplot, and these subplots were weeded regularly to eliminate any vegetation. Shoot competition was eliminated in this study by staking coarse netting over the entire subplots designated as root-competition only. In these subplots, the grass shoots growing around seedlings were pulled back by the netting and provided no shade for the seedlings. This procedure has been used before at Cedar Creek and has been found not to affect above ground biomass of the herbaceous vegetation (Wilson and Tilman 1991).

Eight acorns of Quercus ellipsoidalis were planted into each of the subplots in fall of 2000, one in each of the four root exclusion tubes and four outside the tubes. By growing seedlings both in and outside of tubes, it was possible to determine the extent of any tube effects on oak seedling survival and grass and oak seedling growth.

\section{Water and nitrogen treatments}

During summer 2001, following two years of establishment of the grasses and shortly after the emergence of the oak seedlings, three water levels (dry, medium, and wet) were created and maintained for 54 days (June 21-August 13) through the use of temporary rain exclosures and an irrigation sprinkler system. Dry conditions were created by pulling a 6 mil plastic tarp $(30 \times 6 \mathrm{~m})$ over plots immediately prior to a rainfall, and removing it after the rain ended (Davis et al. 1999). Since the aim was to create drier than normally ambient soil conditions, and not eliminate water input completely, the rain tarps were not applied during every precipitation event. Wet conditions were created by using a commercial irrigation system consisting of plastic tubing and spray nozzles suspended over the plots and connected to an existing irrigation system in this field. One centimeter of water was added to wet plots every third day, unless it had rained during that time period. Due to several weeks without rain, a total of seven centimeter of water were added to the medium plots throughout this period to keep the plots from drying out too much. One centimeter of water was added to the dry plots. The study site received $11.0 \mathrm{~cm}$ of natural rainfall during this period and the combination of natural and supplemented water provided to plots during the 54 days resulted in wet plots receiving $28.0 \mathrm{~cm}$, medium plots receiving $18.0 \mathrm{~cm}$, and dry plots receiving $2.7 \mathrm{~cm}$. These amounts correspond closely with the mean, high, and low annual rainfall amounts recorded for this area of Minnesota during this time period $(30-\mathrm{yr}$ mean [1971-2000] $=19.0 \mathrm{~cm} ; 108-\mathrm{yr}$ high $[1892-2000]=31.7 \mathrm{~cm} ; 108-y r$ low $[1892-$ 2000] $=4.2 \mathrm{~cm}$; data from National Oceanic and Atmospheric Administration, Cambridge, MN station).

Ammonium nitrate granules $\left(\mathrm{NH}_{4} \mathrm{NO}_{3}\right)$ were applied at an annual rate of $5 \mathrm{~g} \mathrm{~m}^{-2} \mathrm{yr}^{-1}$ to the $\mathrm{N}$ enriched subplots during three applications in summer 2001 (June 1, July 1, and August 1). Onethird the annual rate was applied during each of the three applications.

\section{Data collection and compilation}

\section{Seedling survival and morphometrics}

Subplots were censused and oak seedling heights measured on June 21, 2001, the beginning of the water treatment period and they were censused again on August 13, 2001, the end of the water 
treatment period. All seedlings growing in root exclusion tubes were excavated between August 13-16, 2001, dried and separated into below and above ground components. Root length and biomass and shoot height and biomass were determined for each excavated seedling. Since seedlings were excavated less than 3 months after they emerged, the acorn was still attached to most seedlings. The height $(h)$ and width $(w)$ of these acorns were measured and the size (volume) of the acorns was approximated as $h^{*} \pi^{*}(w / 2)^{2}$. The seedlings growing outside the tubes were not harvested, and these seedlings were recensused on August 28, 2002 to determine if the experimental manipulations of nitrogen, water, and grass in 2001 affected survival the following year.

\section{Grass biomass}

At the end of the water treatment period in $\mathrm{Au}-$ gust, 2001, grass shoot biomass was harvested at ground level in a $50 \times 10 \mathrm{~cm}$ strip in each vegetated subplot, dried and weighed. Root biomass was determined by extracting a root core from each vegetated subplot at the same time and washing, drying and weighing the roots (Tilman and Wedin 1991). Grass roots and shoots were also collected from the root exclusion tubes in four of the plot blocks (half of all the subplots) and washed, dried and weighed.

\section{Resource levels}

Soil water content of all subplots were measured weekly during 2001 (June 21-August 13) by measuring percent volumetric soil water content, $\theta$, using a portable time domain reflectometry system $\left(\right.$ Trime $\left.^{\mathrm{TM}}\right)$. Twenty centimeter probes were inserted vertically into the soil surface near the center of each subplot. Soil water measurements were also made inside some of the root exclusion tubes to determine if soil water content was being affected by the tubes. In many sites, soil water (matric) potential $\psi_{\mathrm{s}}$ is a better measure of availability of soil water to plants than volumetric soil water, $\theta$. In this study field, because the coarse soil texture is extremely uniform and the field is flat, analyses using $\theta$ and $\psi_{\mathrm{s}}$ have produced identical results (Davis et al. 1999; Davis and Pelsor 2001). Thus, findings were analyzed and presented based on $\theta$.

Photosynthetically active radiation (PAR, $\mu$ mol photons $\mathrm{m}^{-2} \mathrm{~s}^{-1}$ ) in subplots was measured at the end of the experiment on a single sunny day (August 15, 2001) using a LiCOR LAI2000 Plant Canopy Analyzer. Light measurements were made $15 \mathrm{~cm}$ above the ground, the approximate height of the seedlings at that time. At the end of the experiment, soil samples were taken from each subplot (Aug 13-16) and subsequently analyzed for ammonium and nitrate levels $\left(\mathrm{mg} \mathrm{kg}^{-1}\right.$ soil). Soil $\mathrm{NH}_{4}$ and $\mathrm{NO}_{3}$ (data presented are $\mathrm{NH}_{4}-\mathrm{N}$ and $\mathrm{NO}_{3}-\mathrm{N}$ ) were determined from $0.01 \mathrm{~mol} / 1 \mathrm{KCl}$ extractions of ammonium and nitrate using an AlpKem autoanalyzer (Astoria Pacific, Inc., Clackamas, Oregon, USA).

\section{Data analysis}

The effect of the water, nitrogen, and grass (nonindigenous $\mathrm{C}_{3}$, native $\mathrm{C}_{4}$, and no grass) treatments on resource levels $\left(\theta\right.$, PAR, and $\mathrm{NH}_{4}$ and $\left.\mathrm{NO}_{3}\right)$ were analyzed using a split-plot ANOVA, with water as a whole plot effect and nitrogen and grass as subplot effects. For oak seedlings growing inside tubes, the type of competition (root, shoot, both root and shoot, neither root nor shoot) was added as a subplot effect. Soil water was arcsine transformed and $\mathrm{NH}_{4}$ and $\mathrm{NO}_{3}$ were log-transformed prior to analysis.

The proportion of seedlings that survived in a subplot during the water treatment period (seedlings inside and outside of root exclusion tubes were analyzed separately) was arcsine transformed and used as the survival datum for the respective subplots. (Note: analysis of the survival data using logistic regression and a model that incorporated the split-plot design (\%GLIMMIX macro, SAS Institute, Inc.) failed due to lack of convergence during the runs. The lack of convergence was due to the large number of subplots that exhibited either complete survival or complete mortality of all seedlings (Oliver Schabenberger, SAS Institute, Inc, personal communication). As a result, survival data were analyzed using a split-plot ANOVA as described above.)

The subplot means of four seedling morphometrics (root mass, root length, shoot mass, and increase in shoot height during the water treatment period) measured on the surviving seedling in a subplot were used as the growth data for the respective subplots. Effects of water, nitrogen, grass functional group, and type of competition on 
these measures of seedling growth were analyzed using a split-plot ANOVA, with acorn size and shoot height at the beginning of the water treatment period being included as covariates. Root and shoot mass were log transformed for the analyses. Multiple regression analyses were conducted to reveal patterns of seedling growth and survival in relation to resource availability (PAR, soil water, $\mathrm{NO}_{3}, \mathrm{NH}_{4}$ ), acorn size, and initial seedling size.

In a few instances, a split-split-plot analysis (water $=$ whole plot factor, grass type and nitrogen $=$ subplot factor, 'tube' or 'no tube' = subsubplot factor) or paired $t$-test was conducted to determine if there were any tube or netting effects on the variables of interest. All statistical analyses were conducted using JMP ${ }^{\mathrm{TM}}$ (SAS Institute, Inc.). Differences between multiple means in ANOVAs were tested using the Tukey test $(p<0.05)$. All errors presented are standard errors.

\section{Results}

\section{Resources}

\section{Soil water}

Percent soil water, $\theta$, was affected by a water $\times$ grass (non-indigenous, native, no grass) interaction $(F=23.76, p<0.0001$, Figure 1a). Soil water did not differ between non-indigenous and native grass subplots in the three water environments. However, while weeded subplots exhibited comparable soil water levels to the non-indigenous and native grass subplots under wet conditions, they exhibited higher levels in dry and medium subplots (Figure 1a). Soil water was also affected by a grass $\times$ nitrogen interaction $(F=5.42$, $p=0.0049$, Figure 1b). In the weeded subplots, $\theta$ did not differ between the ambient nitrogen and nitrogen supplemented conditions, while in the non-indigenous and native grass subplots $\theta$ was 15-20\% higher in the ambient nitrogen conditions (Figure 1b). Comparisons of soil water inside and outside of tubes from 30 subplots including subplots in dry, medium, and wet conditions, showed no tube effect on soil water $(t=0.65, p=0.27$, $n=30$ pairs, paired $t$-test).

\section{Light}

PAR was affected by the grass treatment $(F=66.15, p<0.0001$, Figure 2a) with PAR
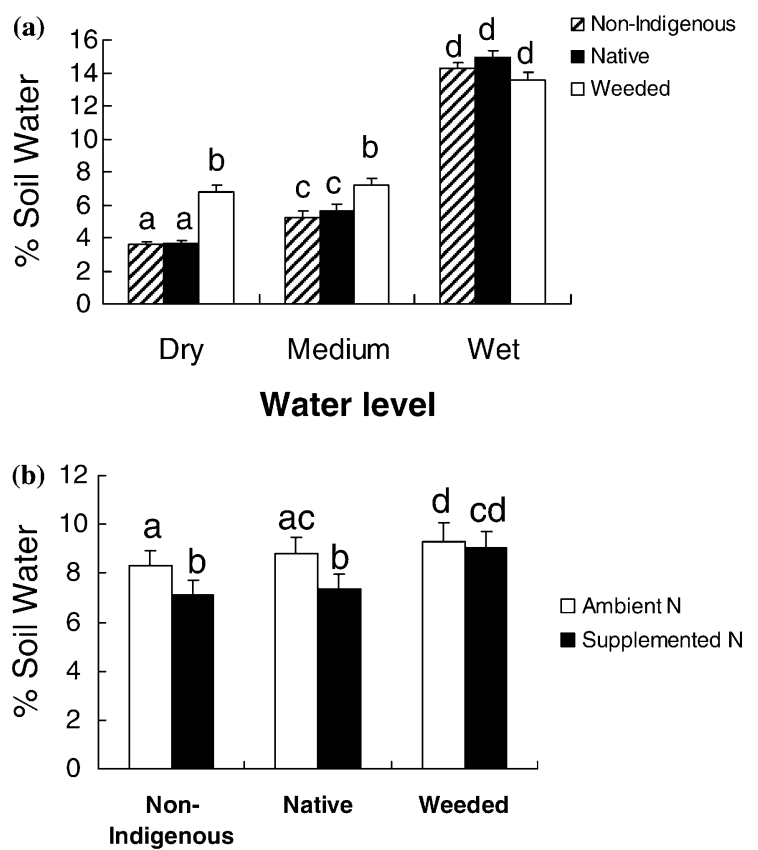

Subplot Type

Figure 1. Mean Percent soil water (volumetric soil water content, $\theta$ ) in non-indigenous and native grass subplots and weeded subplots shown for the three water treatment levels (a). Mean percent soil water in nitrogen supplemented and ambient subplots shown for the non-indigenous and native grass subplots and weeded subplots (b).

levels significantly lower in native grass subplots compared to the non-indigenous grass subplots, which naturally were significantly lower than in the weeded subplots. Light was not affected by the water or nitrogen treatments $(p>0.05)$ when all subplots are included in the analysis. However, if the weeded subplots are excluded from the analysis, there is a significant nitrogen effect on light ( $\mathrm{N}$ supplemented: $759 \pm 42.8 \mu \mathrm{mol}$ photons $\mathrm{m}^{-2} \mathrm{~s}^{-1} ;$ ambient $\mathrm{N}: \quad 869 \pm 39.8 \mu \mathrm{mol}$ photons $\mathrm{m}^{-2} \mathrm{~s}^{-1} ; F=3.83, p=0.05$ ).

\section{Soil nitrogen}

Soil $\mathrm{NH}_{4}$ levels were significantly affected by the grass factor $(F=8.28, p=0.0003$, Figure $2 b)$, with $\mathrm{NH}_{4}$ levels being higher in the non-indigenous grass subplots than the native grasssubplots. Ammonium levels were also significantly affected by the nitrogen treatment ( $\mathrm{N}$ supplemented: $0.34 \pm 0.022 \mathrm{mg} \mathrm{kg}^{-1}$ soil; ambient $\mathrm{N}: 0.27 \pm$ $0.015 \mathrm{mg} \mathrm{kg}^{-1}$ soil; $F=17.53, p<0.0001$ ). Soil 

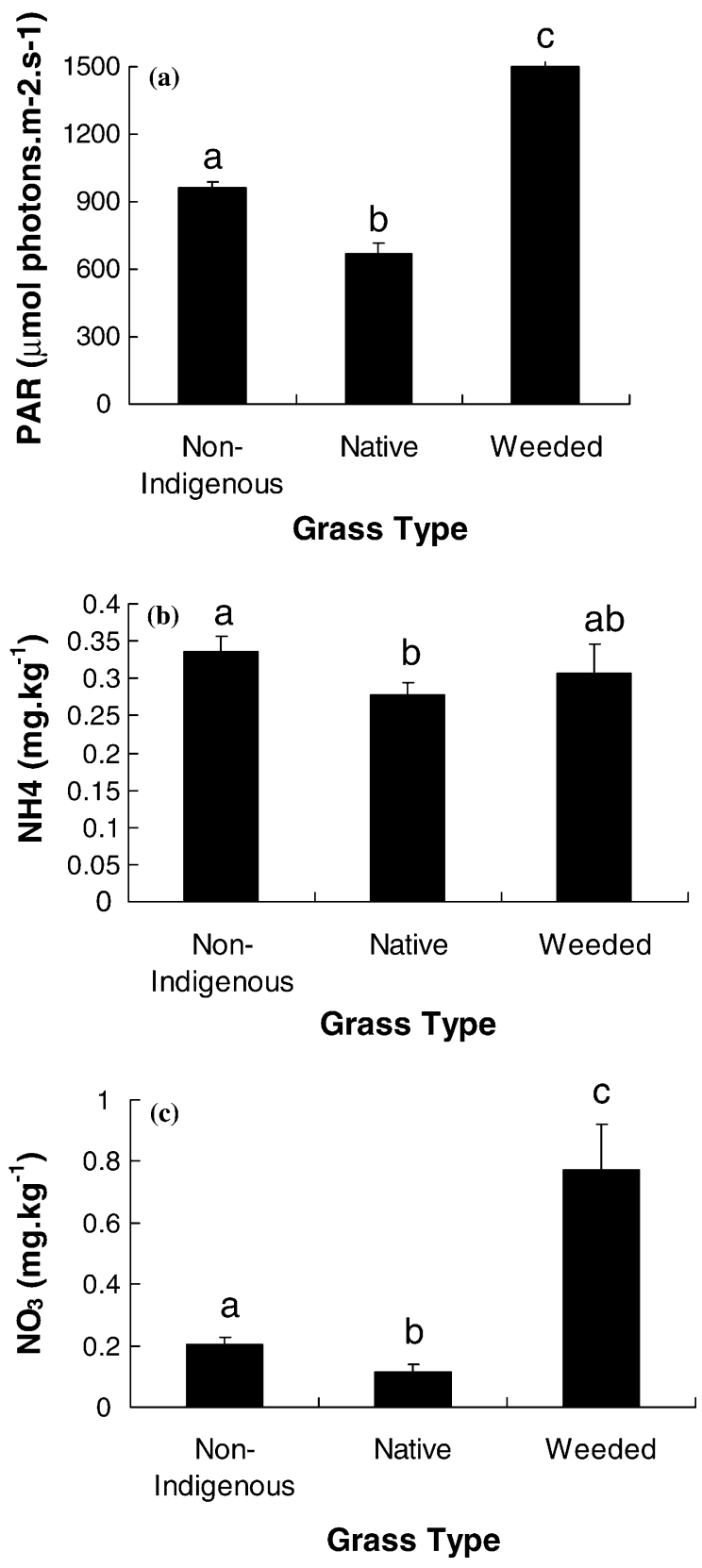

Figure 2. Mean resource levels ( $\mathrm{PAR}, \mathrm{NH}_{4}$ and $\mathrm{NO}_{3}$ ) measured at the end of the 54-day experimental period in non-indigenous and native grass subplots and weeded subplots.

$\mathrm{NO}_{3}$ levels were also significantly affected by the grass factor, with $\mathrm{NO}_{3}$ levels being higher in the non-indigenous grass subplots than the native grass subplots $(F=97.98, \quad p<0.0001$, Figure $2 \mathrm{c})$. Nitrate levels were also affected by an interaction between the water and nitrogen factors
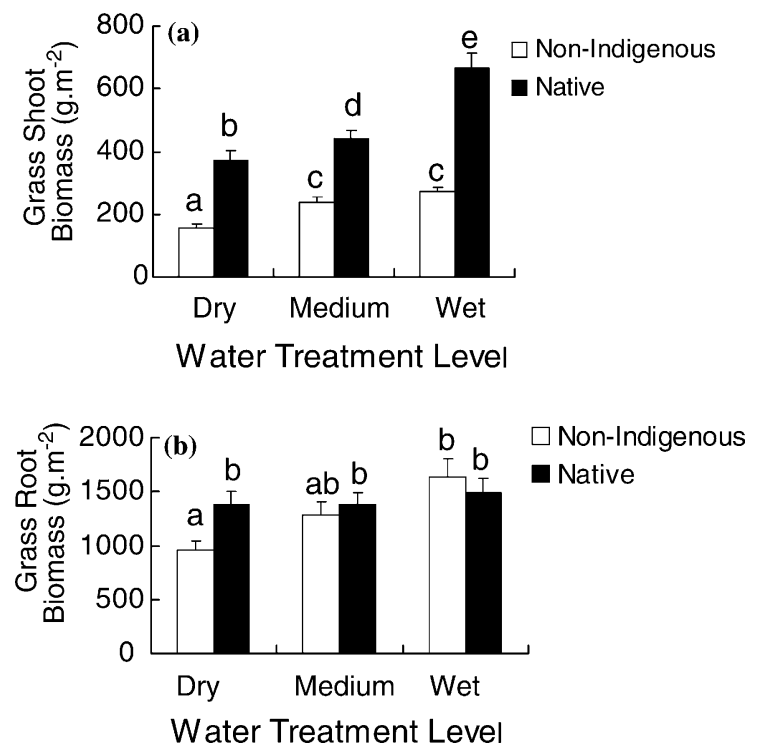

Figure 3. Mean grass shoot (a) and root (b) biomass in the nonindigenous and native grass subplots shown for the three water treatment levels.

$(F=7.22, p=0.0009)$. Although $\mathrm{NO}_{3}$ levels did not differ between the nitrogen supplemented and ambient nitrogen subplots in the medium and wet plots, nitrate levels were higher in the nitrogen supplemented subplots under dry conditions (Tukey test, $p<0.05$ ).

Response of grasses to water and nitrogen treatments

Grass shoot biomass was affected by a water $x$ grass interaction $(F=3.10, p=0.047)$ with the larger proportional difference in shoot biomass in non-indigenous grass subplots occurring between dry and medium water conditions, whereas the largest proportional difference in native grass subplots occurred between medium to wet conditions (Figure 3a). Grass shoot biomass was also significantly higher in the nitrogen supplemented subplots $\left(390.6 \pm 22.0 \mathrm{~g} \mathrm{~m}^{-2}\right)$ than in the ambient nitrogen subplots $\left(324.6 \pm 20.4 \mathrm{~g} \mathrm{~m}^{-2}\right.$, $F=27.31, p<0.0001)$.

Grass root biomass was also affected by a water $\times$ grass interaction $(F=3.39, p=0.035$, Figure $3 b)$. Root biomass of non-indigenous grasses were much more responsive to changes in water input, increasing in biomass by more than 
Table 1. Results of the split-plot ANOVA showing the effects of the different treatments on oak seedling survival.

\begin{tabular}{|c|c|c|c|c|c|}
\hline Effect & df & SS & MSS & $F$ & $p$ \\
\hline Grass & 1 & 2.06 & 1.03 & 19.33 & $<0.0001$ \\
\hline Competition & 2 & 3.02 & 1.51 & 14.17 & $<0.0001$ \\
\hline Grass $*$ Competition & 2 & 0.54 & 0.27 & 2.54 & 0.0812 \\
\hline Nitrogen & 1 & 0.27 & 0.135 & 2.56 & 0.1111 \\
\hline Grass * Nitrogen & 1 & 0.09 & 0.045 & 0.84 & 0.3613 \\
\hline Competition $*$ Nitrogen & 2 & 0.13 & 0.065 & 0.60 & 0.5505 \\
\hline Grass $*$ Competition * Nitrogen & 2 & 0.05 & 0.025 & 0.81 & 0.8051 \\
\hline Water & 2 & 26.50 & 13.25 & 61.83 & $<0.0001$ \\
\hline Grass $*$ Water & 2 & 2.21 & 1.105 & 10.37 & $<0.0001$ \\
\hline Competition $*$ Water & 4 & 6.27 & 1.5675 & 14.70 & $<0.0001$ \\
\hline Grass $\times$ Competition * Water & 4 & 0.37 & 0.0925 & 0.86 & 0.4874 \\
\hline Nitrogen $*$ Water & 2 & 0.12 & 0.06 & 0.58 & 0.5955 \\
\hline Grass $*$ Nitrogen $*$ Water & 2 & 0.14 & 0.07 & 0.66 & 0.5196 \\
\hline Competition $*$ Nitrogen $*$ Water & 4 & 0.67 & 0.1675 & 1.57 & 0.1839 \\
\hline Grass $*$ Competition $*$ Nitrogen $*$ Water & 4 & 0.36 & 0.09 & 0.85 & 0.4922 \\
\hline Rep (Block) & 7 & 2.12 & 0.303 & 2.83 & 0.0077 \\
\hline Rep $*$ Water & 14 & 3.00 & 0.214 & 2.01 & 0.0186 \\
\hline Mean shoot height (062101) & 1 & 0.56 & 0.56 & 0.52 & 0.4701 \\
\hline
\end{tabular}

$70 \%$ from the dry to the wet environments and showed significant increases in root biomass at each of the two increases in water input, whereas the root mass of native grasses increased by only $11 \%$ from the dry to the wet environments and showed no increase in root biomass from the dry to medium water environments (Figure $3 \mathrm{~b}$ ). There was no nitrogen effect on grass root biomass $(F=2.75, p=0.0984)$.

Comparisons of root and shoot biomass of grass growing inside and outside of tubes in subplots experiencing both root and shoot competition, including both grass groups and various combinations of nitrogen and water, showed no tube effect on root biomass $(t=0.77, p=0.44$, paired $t$-test, $n=42)$ or shoot biomass $(t=0.31, p=0.76$, paired $t$-test, $n=42$ ). Similar comparisons showed no netting effect on grass root or shoot biomass, for grass growing outside the tubes (96 subplots with netting, 192 subplots without netting) (root mass: $t=1.03, \quad p=0.30 ; \quad$ shoot mass: $t=0.66$, $p=0.51)$ or for grass growing inside tubes (44 subplots with tubes with netting, 41 subplots with tubes without netting) (root mass: $t=0.46$, $p=0.65$; shoot mass: $t=1.83, p=0.07$ ).

\section{Oak seedling survival}

A split-split-plot analysis of seedling survival for seedlings growing in subplots experiencing both root and shoot competition $(n=188)$ showed that there was no tube effect on oak seedling survival $(F=0.61, p=0.44)$. Since the survival results for seedlings growing inside and outside the tubes were comparable, results are only reported are for seedlings growing inside the tubes.

During the 54-day experimental water treatment period, virtually all seedlings growing in weeded subplots survived, irrespective of water and nitrogen treatments (survival $=99.4 \%, \quad \mathrm{~N}=$ 171). An analysis of treatment effects on seedling survival (June 21-Aug 13) for all non-indigenous grass and native grass subplots (excluding weeded subplots) showed there was a water $\times$ grass effect (Table 1, Figure 4a) with seedlings growing in non-indigenous grass subplots exhibiting much lower survival in dry conditions compared to medium and wet conditions, whereas seedlings growing in native subplots did not experience as severe a decline in survival in the dry environments. In addition to the water $\times$ grass interaction, the analysis revealed a water $\times$ competition interaction (Table 1, Figure 4b), with seedling survival being considerably reduced in dry conditions for those seedlings experiencing root competition only or root and shoot competition combined. In contrast, the survival of seedlings experiencing only shoot competition was reduced only slightly in dry conditions (Figure 4b). Seedling survival was not affected by $\mathrm{N}$ addition 

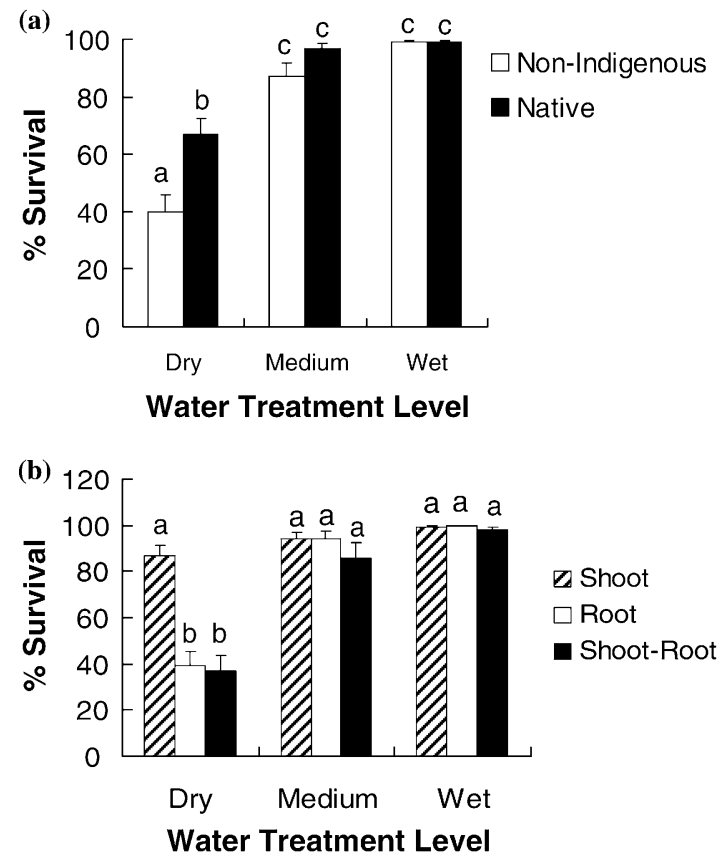

Figure 4. Mean percent survival for oak seedlings growing in non-indigenous and native grass subplots (a) and in the three different types of competition (shoot, root, shoot and root combined) from surrounding grass (b) shown for the three water treatment levels.

$(F=2.57, p=0.11)$, or by initial seedling size $(F=0.52, p=0.47)($ Table 1$)$.

\section{Oak seedling survival vs. resources}

The multiple regression analysis of seedling survival during the 54-day experimental period showed that survival was strongly positively associated with soil water $(F=37.68, p<0.0001$, $n=257$ subplots) but not with any of the other resources (IPAR, $\mathrm{NO}_{3}, \mathrm{NH}_{4}$ ) or seedling size at the start of the experimental period $(p>0.10)$.

\section{Oak seedling survival August 2001-August 2002}

The water and nitrogen treatments ceased on August 13, 2001. A recensus in August 2002 of seedlings that were alive on August 13, 2001 showed that none of the 2001 experimental factors (water, nitrogen, and grass type) affected oak seedling survival during the following year, ( $p>0.15$ for all factors, split-plot ANOVA).

\section{Oak seedling growth}

\section{Shoot growth}

Oak seedling shoot growth, measured by the increase in oak shoot height during the 54-day water treatment period, was influenced by a three-way interaction involving grass, nitrogen, and water $(F=3.86, p=0.023)$. Figure 5a shows a trend for increasing shoot growth along the soil water gradient for oak seedlings growing in non-indigenous $\mathrm{C}_{3}$ grasses under ambient $\mathrm{N}$ conitions. However, no trend of shoot growth was exhibited for these seedlings when growing under $\mathrm{N}$ enriched conditions (Figure 5a). Conversely, the results showed a trend for increasing shoot growth along the soil water gradient for oak seedlings growing in native $\mathrm{C}_{4}$ grasses under the $\mathrm{N}$ enriched conditions (Figure 5a).

The multiple regression analysis showed that shoot growth during the 54-day water treatment period was positively associated with soil water and negatively associated with shoot height at the beginning of the water treatment period (Table 1). Shoot growth was not associated with acorn size, or PAR, $\mathrm{NH}_{4}$, or $\mathrm{NO}_{3}$ levels (Table 2).

\section{Shoot biomass}

Shoot biomass was affected by a nitrogen $\times$ water interaction $(F=3.73, \quad p=0.026$, Figure $5 b)$, with shoot biomass showing a more consistent positive relationship to water input in ambient nitrogen subplots (Figure 5b). There was also a significant grass effect with shoot biomass being about $7 \%$ greater in the native grass subplots (native subplots: $0.225 \pm 0.006 \mathrm{~g}$; non-indigenous subplots: $0.211 \pm 0.006 ; F=4.30, p=0.040)$. In addition, there was a competition effect $(F=6.34$, $p=0.002$ ), with shoot biomass being approximately $18 \%$ greater in subplots experiencing only shoot competition compared to subplots experiencing both root and shoot competition (Figure 5c).

Oak seedling shoot biomass was positively associated with stem height at the beginning of the experimental period and the size of the acorn and negatively correlated with $\mathrm{NO}_{3}$, but was not correlated with PAR or $\mathrm{NH}_{4}$ levels (Table 2). 


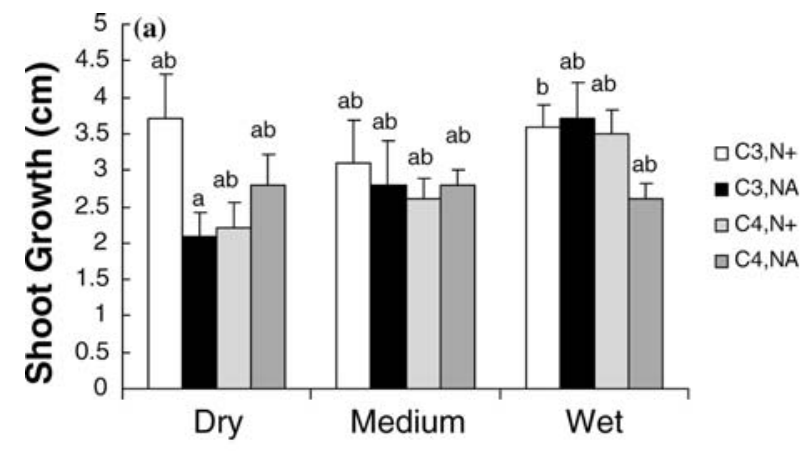

Water Treatment Level

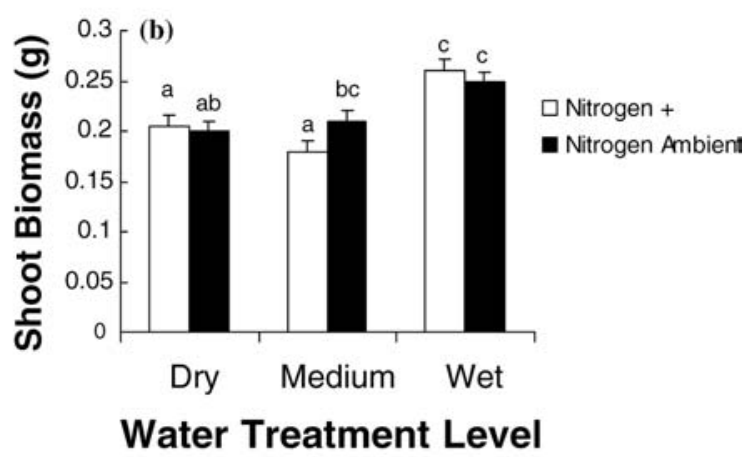

Water Treatment Level

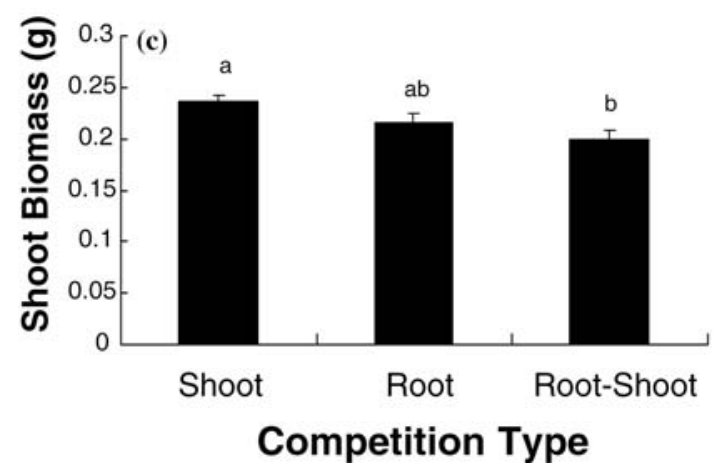

Figure 5. Mean shoot growth of oak seedlings growing in non-indigenous and native grass subplots in both nitrogen supplemented and ambient conditions shown for the three water treatment levels (a). Mean shoot biomass of seedlings growing in nitrogen supplemented and ambient subplots shown for the three water treatment levels (b). Mean shoot biomass of the seedlings shown as a function of the type of competition they experienced from the grasses (c).

Table 2. Results of a multiple regression analysis of four growth measurements of the oak seedlings showing the relationship of the respective morphometrics to resource levels, acorn size, and shoot height at the start of the experimental period (June 21, 2001).

\begin{tabular}{lcccc}
\hline & Shoot growth & Shoot mass & Root length & Root mass \\
\hline Soil Water & $9.27^{*}(+)$ & $26.07^{* * *}(+)$ & 1.68 & $25.07^{* * *}(+)$ \\
PAR & 0.04 & 2.41 & 1.17 & 2.72 \\
$\mathrm{NO}_{3}$ & 0.45 & $6.36^{*}(-)$ & 0.05 & $6.20^{*}(-)$ \\
$\mathrm{NH}_{4}$ & 0.13 & 0.01 & 1.92 & 0.95 \\
Acorn size & 1.29 & $20.57^{* * *}(+)$ & 2.67 & $10.97 * *(+)$ \\
Shoot height $(062101)$ & $63.57^{* * *}(-)$ & $36.35^{* * *}(+)$ & $6.55^{*}(+)$ & $19.74^{* * *}(+)$ \\
\hline
\end{tabular}

Data are based on the mean values of surviving seedlings in 223 subplots. Shoot growth represents the change in shoot height from the beginning to the end of the 54-day experimental period. Shoot and root mass and root length were measured from seedlings excavated at the end of the experimental period. Shown are the $F$ values resulting from the analysis. Significance levels are indicated with asterisks $(*=0.05, * *=0.01, * * *=0.001)$. Significant positive and negative associations are indicated with plus and minus signs, respectively.

\section{Root length}

Root length was affected by a water $\times$ grass interaction $(F=3.54, p=0.0314$, Figure 6a). Although root length was longest in wet conditions in both non-indigenous and native grass subplots, in the non-indigenous grass subplots, root length was shortest in the medium water conditions while in the native grass subplots, root length was shortest in the dry subplots. Root length was also affected individually by competition type $(F=9.54, p=0.0001)$ and nitrogen $(F=6.93, p=0.0093)$. Root lengths in subplots 

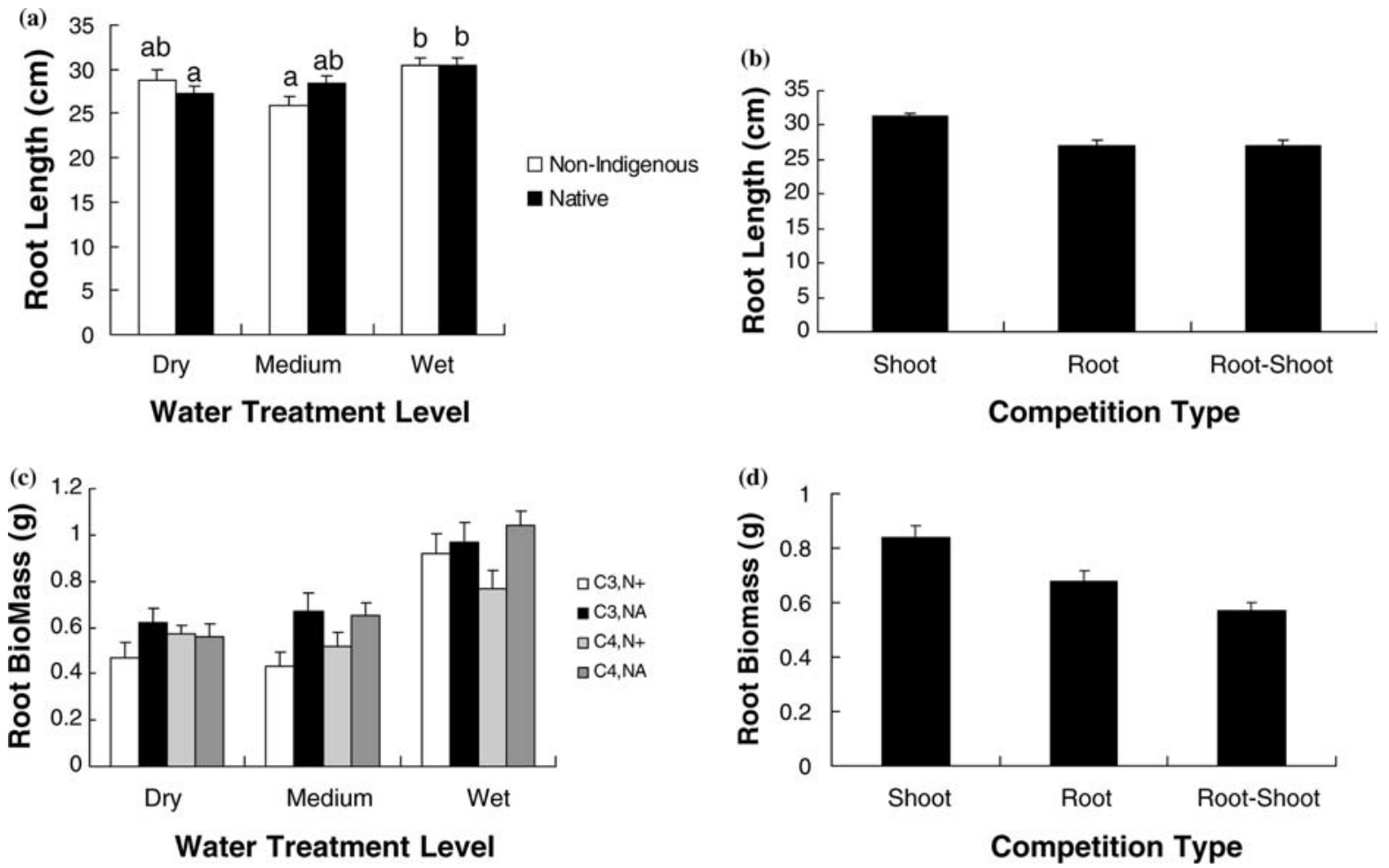

Figure 6. Mean root length of oak seedlings growing in non-indigenous and native grass subplots shown for the three water treatment levels (a). Mean root length of the seedlings shown as a function of the type of competition they experienced from the grasses (b). Mean root biomass of the seedlings growing in non-indigenous and native grass subplots in both nitrogen supplemented and ambient conditions shown for the three water treatment levels (c). Mean root biomass of the seedlings shown as a function of the type of competition they experienced from the grasses (d).

with only shoot competition were approximately $15 \%$ longer than in subplots with both root and shoot competition or with root competition alone (Figure 6b). Root lengths in ambient nitrogen subplots were approximately $5 \%$ longer than in nitrogen supplemented subplots.

Root length was not associated with any of the resource levels, nor with acorn size, but was positively associated with shoot height at the start of the water treatment period (Table 2).

\section{Root biomass}

Root biomass was affected by a three-way interaction involving grass, nitrogen, and water $(F=5.22, p=0.0063$, Figure 6c). In ambient nitrogen subplots, oak seedling root biomass varied little between non-indigenous and native grass subplots in any of the three water environments, while in the nitrogen supplemented subplots, oak seedling root biomass in dry and medium water conditions tended to be greater when growing in native grasses (Figure 6c), while in wet conditions seedling root biomass tended to be greater in nonindigenous grasses. Root biomass was also affected by competition $(F=24.72, p<0.0001)$ with root biomass being higher in subplots experiencing only shoot competition and lowest in subplots experiencing both root and shoot competition (Figure 6d).

Root biomass was positively associated with soil water, acorn size, and shoot height at the beginning of the water treatment period, and negatively associated with $\mathrm{NO}_{3}$ (Table 1). Root biomass was not associated with PAR or $\mathrm{NH}_{4}$ levels (Table 2).

\section{Discussion}

Grass type (non-indigenous $\mathrm{C}_{3}$ or native $\mathrm{C}_{4}$ ) variously affected some of the different oak seedling 
growth measurements, e.g., seedling shoot biomass was greater in $\mathrm{C}_{4}$ subplots. However, there were no substantial growth differences among seedlings growing in the non-indigenous or native grass subplots. The results showed that of the resources measured, only soil water was consistently and positively correlated with seedling growth (Table 2). Kloss and McBride (2002) reported that seedling growth (including root and shoot mass and shoot height) of Quercus doublasii was also strongly positively associated with soil water.

There was a consistent relationship between seedling growth and acorn size, with both root and shoot biomass strongly and positively correlated with acorn size. Early shoot height, measured on June 21 prior to the beginning of the experimental period, was also positively correlated with acorn size. That several growth measurements were positively associated with acorn size shows a strong maternal effect on early seedling growth for this species.

The most striking finding of the study was the sharp reduction in oak seedling survival under drought conditions, and to a lesser degree under medium water conditions, for seedlings growing in non-indigenous grasses compared to those growing in native grasses. Soil water was also the only resource consistently and positively correlated with seedling survival. These findings are consistent with previous findings that soil water is a key limiting resource for establishment of plants at Cedar Creek (Davis et al. 1998, 1999; Davis and Pelsor 2001). The reduced survival of the oak seedlings in the non-indigenous subplots in this study is consistent with the findings of McArthur et al. (1995), who concluded that the establishment of woody plants in western Wyoming grasslands was inhibited by competition from non-indigenous grass species, in fact the same three non-indigenous species used in this study $(P$. pratensis, $B$. inermis, $P$. pratense). Thus, our findings supported our initial hypothesis that the non-indigenous grasses were contributing to the very low establishment rates of trees in Cedar Creek's old fields. In a similar study conducted at Cedar Creek (Mark Ritchie, unpublished data), oak seedling survival was also found to be lower in non-indigenous cool-season grasses compared to seedlings growing in native warm-season grasses. However, the findings from our study did not support our hypothesis that the non-indigenous grasses were reducing tree establishment by reducing the availability of resources.

Seedling survival was not associated with available soil nitrogen or light. Given that oak seedling survival was strongly positively associated with water in this and other studies (Davis et al. 1999; Danner and Knapp 2003), we expected that the reduced seedling survival in the non-indigenous grasses under dry and normal conditions would have been associated with depressed soil water levels. However, as the results showed, soil water levels were the same in the non-indigenous and native grasses subplots (Figure 1). Thus, from a resource availability perspective (Davis et al. 1998), the findings appear to present a paradox, in which seedling survival, which was strongly affected by grass type (non-indigenous or native), was not affected by the resources differentially affected by the grass groups (PAR, $\mathrm{NO}_{3}, \mathrm{NH}_{4}$ ). At the same time seedling survival was strongly affected by the one resource (water) that was not differentially affected by the two grass groups. Moreover, in the dry subplots, in which oak seedling survival was most suppressed in the nonindigenous grasses, levels of $\mathrm{NO}_{3}, \mathrm{NH}_{4}$, and light were significantly higher in the non-indigenous grass subplots. The non-indigenous grass plots would seem to have been a much less competitive, and hence much more favorable, environment for the emerging oak seedlings.

If root morphology of the oak seedlings differed between the non-indigenous and native grass subplots, it is possible this could influence the respective seedlings' ability to sequester water. We did not excavate and examine dead seedlings, but based on the measurements of surviving seedlings, total oak root biomass in dry and medium environments was approximately $20 \%$ greater in native grasses under nitrogen-enriched conditions, suggesting that this might be an explanation for the increased survival in native grasses. However, under ambient nitrogen conditions, oak root biomass did not differ between the two grass functional groups. Since seedling survival was lower in the non-indigenous grass subplots under both ambient and nitrogen-enriched conditions, differences in root morphology cannot be the explanation for seedling survival differences between the non-indigenous and native grass subplots.

Another possible explanation for the survival differences could be that, because the native plants 
intercepted more light in the dry subplots, they reduced water stress on the seedlings, i.e., by producing a nurse plant effect (Bertness and Callaway 1994; Holmgren et al. 1997; Danner and Knapp 2003). Seedling survival was slightly higher in native grass subplots when seedlings experienced only shoot competition from the grasses ( $81 \%$ in the non-indigenous grass subplots vs. $95 \%$ in the native grass subplots). However, reduced water stress through shading cannot be the primary explanation for the oak seedlings' success in the native grass subplots since in subplots where shoot competition was eliminated (and hence there could be no reduction in water stress due to shading), the survival of seedlings in the native grass dry plots $(50 \%)$ was double that in the non-indigenous grass dry plots $(25 \%)$.

Ritchie (personal communication) reported that oak seedling tissue $\mathrm{N}$ was higher in in seedlings growing in non-indigenous $\mathrm{C}_{3}$ grasses compared to those growing in native $\mathrm{C}_{4}$ grasses, raising the possibility of increased transpirational demand by seedlings growing in the non-indigenous grass plots, which might make the seedlings more vulnerable to short-term water stress. This hypothesis would predict that seedling survival would be affected by a nitrogen $\times$ water interaction, with water limitation reducing survival more in nitrogen-enriched than nitrogen-ambient conditions. However, in our study, seedling survival was not affected by the nitrogen treatment.

A follow-up pot study conducted in summer 2003 showed that negative effects of the nonindigenous grasses on $Q$. ellipsoidalis seedlings growing in dry conditions occurred whether the seedlings were growing in pots containing soil and the non-indigenous grasses (both soil and grass excavated from the original study subplots) or they were growing in pots containing only the soil from non-indigenous grass subplot (also excavated from the original non-indigenous grass plots) (Davis unpublished data). Thus, results to date suggest that the non-indigenous grass species are altering the soil environment in some way that is deleterious to the emerging oak seedlings.

The differential oak seedling survival in the nonindigenous and native grass subplots might be due to underground processes associated with soil organisms (Bever et al. 1997) that are known to be affected by the composition of the resident plant species (Westover et al. 1997; Grayston et al.
2001). Since soil pathogens can reduce survival of tree seedlings (Augspurger 1984; Packer and Clay 2000) and reduce the abundance of trees relative to herbaceous vegetation (Weste 1986), it is possible that pathogenic infection rates differed between the non-indigenous and native grass subplots. At Cedar Creek, Johnson et al. (1991) found that different grass species support different the communities of vesicular-arbuscular mycorrhizal (VAM) fungi, and, in particular, that VAM fungi communities differed between garden plots composed of Schizachyrium scoparium and Poa pratensis, respectively (Johnson et al. 1992). Thus, another possible explanation for the survival differences between the two grass functional groups could involve differences in VAM fungi communities in the non-indigenous and native grass subplots that may have affected nutrient and/or water uptake by the seedlings. Other explanations for the reduced seedling success in the non-indigenous grasses could involve allelopathy (Callaway and Aschehoug 2000) and/or differences in the type or extent of herbivory on oak seedling roots in the non-indigenous and native grass subplots. Future studies are needed to test the possible importance of these other factors.

\section{Summary}

Recent data have shown that soil water levels in North American grasslands exhibit a high degree of temporal variability, partly due to the ability of grasses to amplify the effects of temporal variation in rainfall through their uptake of water during dry conditions (James et al. 2003). In the northern Great Plains, short-term drought is a common phenomena during the summer months. It has been proposed that periodic low levels of soil water may prevent woody plant establishment in some grasslands (McPherson 1997; Wilson 2000), although few studies have investigated this possibility. This study showed that short-term droughts can cause significant mortality of recently germinated oak seedlings and that this impact is significantly exacerbated when the seedlings are growing in non-indigenous cool-season grasses as opposed to native warm-season grasses.

Although the specific factors responsible for the seedling survival differences in the two grass groups under drought conditions have not yet been 
identified, they almost certainly involve underground processes. The data make it clear that the effects of the ecological mechanism(s) are strongly mediated by soil water levels since the effects were greatest under dry conditions and they disappeared completely in wet plots, in which virtually all seedlings survived, whether in non-indigenous or native grass subplots. There were no second-year survival differences between seedlings in the non-indigenous and native grass subplots, during which the summer (2002) was extremely wet, with natural precipitation exceeding the experimental wet conditions in 2001 (NOAA, Cambridge, MN station). The comparable seedling survival rates in the native and nonindigenous subplots under naturally wet conditions are consistent with the 2001 experimental results. Thus, the results show that the decline of native warm-season grasses and the increase of nonindigenous cool-season grasses in this water-limited environment (which has been due to the conversion of native grasslands and savannas to agriculture and then to old fields) is likely influencing successional patterns and processes by impeding the encroachment of oaks into Cedar Creek's old fields, particularly during periods of drought. These results have implications for efforts to restore native savannas by emphasizing the importance of considering the composition of the grass matrix in which oak seedlings might be planted.

A study of oak encroachment in Kansas native grasslands found that although drought may negatively affect oak establishment, the oak seedlings are likely capable of tolerating the projected drier climate in the future, and thus forest expansion into the grasslands is likely to continue (Danner and Knapp 2003). While the same may hold true in grassland openings in native savannas and woodlands in Minnesota, a different scenario seems more likely in old fields located on coarse-grained soils. The results from this study indicate that, in the face of projected hotter and drier summers for the upper Midwest (Kling et al. 2003), the resistance of these old fields to oak encroachment will likely only increase in the future.

\section{Acknowledgements}

We thank Claudia Curran, Andy Miller, Andrea Tietmeyer, Melissa Pelsor, Lee Dooley, Marjorie
Hundtoft, Ingrid Attleson, Jessie Knoll, David Bosanko, Troy Mielke, Dan Bahauddin, and Dale Krueger for their invaluable assistance in the field with this project, Steve Bauer for conducting the soil analyses, Oliver Schabenberger for statistical advice, and Scott Wilson and three anonymous reviewers for their helpful suggestions on the manuscript. This research was supported by the National Science Foundation Ecology Program (DEB 98-73673 M.A.D) and by NSF LTER Grant DEB 96-29566.

\section{References}

Archer S. 1989. Have southern Texas savannas been converted to woodlands in recent history? Am. Natural. 134: 545-561. Augspurger C.K. 1984. Seedling survival of tropical tree species: interactions of dispersal distance, light gaps, and pathogens. Ecology 65: 1705-1712.

Barkley T.M. (ed.). 1986. Flora of the Great Plains. University Press of Kansas, Lawrence, Kansas.

Bastl M., Kocar P., Prach K. and Pysek P. 1997. The effect of successional age and disturbance on the establishment of alien plants in man-made sites: an experimental approach. In: Brock J.H., Wade M., Pysek P. and Green D. (eds), Plant Invasions: Studies from North America and Europe. Backhuys Publishers, Leiden, The Netherlands, pp. 191-201.

Bertness M.D. and Callaway R. 1994. Positive interactions in communities. Trends Ecol. Evol. 9: 191-193.

Bever J.D., Westover K.M. and Antonovics J. 1997. Incorporating the soil community into plant population dynamics: the utility of the feedback approach. J. Ecol. 85: 561-573.

Callaway R.M. and Aschehoug E.T. 2000. Invasive plants versus their new and old neighbors: a mechanism for exotic invasion. Science 290: 521-523.

Christian J.M and Wilson S.D. 1999. Long-term ecosystem impacts of an introduced grass in the northern great plains. Ecology 80: 2397-2407.

Curtis J.T. 1959. The Vegetation of Wisconsin. University of Wisconsin Press, Madison.

D'Antonio C.M. and Vitousek P.M. 1992. Biological invasions by exotic grasses, the grass/fire/cyle, and global change. Annu. Rev. Ecol. System. 23: 63-87.

Danner B.T. and Knapp A.K. 2003. Abiotic constraints on the establishment of Quercus seedlings in grassland. Global Change Biol. 9: 266-275.

Davis M.A., Duke A., Ibsen T., Tran H. and Rhodes R. 1997. Spatial distribution of Penstemon grandiflorus (Nutt.) and Geomys bursarius in a fragmented oak woodland in Minnesota, USA. Nat. Areas J. 17: 136-143.

Davis M.A. and Pelsor M. 2001. Experimental support for a resource-based mechanistic model of invasiblity. Ecol. Lett. 4: $421-428$.

Davis M.A., Thompson K. and Grime J.P. 2001. Charles S. Elton and the dissociation of invasion ecology from the rest of ecology. Div. Distrib. 7: 97-102. 
Davis M.A., Wrage K.J. and Reich P.B. 1998. Competition between tree seedlings and herbaceous vegetation: support for a theory of resource supply and demand. J. Ecol. 86: 652661.

Davis M.A., Wrage K.J., Reich P.B., Tjoelker M.G., Schaeffer T. and Muermann C. 1999. Survival, growth, and photosynthesis of tree seedlings competing with herbaceous vegetation along a water-light-nitrogen gradient. Plant Ecol. 145: 341-350.

del Moral R. 1985. Competitive effects on the structure of subalpine meadow communities. Can. J. Bot. 63: 1444-1452.

de Steven D. 1991. Experiments on mechanisms of tree establishment in old, field succession: seedling survival and growth. Ecology 72: 1076-1088.

Ganade G. and Brown V.K. 2002. Succession in old pastures of central Amazonia: role of soil fertility and plant litter. Ecology 83: 743-754.

Gill D.S. and Marks P.L. 1991. Tree and shrub seedling colonization of old fields in central New York. Ecol. Monogr. 62: 183-205.

Goldberg D.E. and Gross K.L. 1988. Disturbance regimes of mid-successional old fields. Ecology 69: 1677-1688.

Gordon D.R., Welker J.M., Menke J.W. and Rice K.J. 1989. Competition for soil water between annual plants and blue oak (Quercus douglasii) seedlings. Oecologia 79: 533-541.

Grayston S.J., Griffith G.S., Mawdsley J.L., Campbell C.D and Bardgett R.D. 2001. Accounting for variability in soil microbial communities of temperate upland grassland ecosystems. Soil Biol. Biochem. 33: 533-551.

Grigal D.F., Chamberlain L.M., Finney H.R., Wroblewki D.V. and Gross E.R. 1974. Soils of the Cedar Creek Natural History Area. Miscellaneous Report 123, University of Minnesota Agricultural Experiment Station, St. Paul, Minnesota.

Hobbs R.J. and Huenneke L.J. 1992. Disturbance, diversity and invasion: implications for conservation. Conserv. Biol. 6: 324-337.

Holmgren M., Scheffer M. and Huston M.A. 1997. The interplay of facilitation and competition in plant communities. Ecology 78: 1966-1975.

Inouye R.S., Allison T.D. and Johnson N.C. 1994. Old field succession on a Minnesota sand plain: effects of deer and other factors on invasion by trees. Bull. Torrey Bot. Club 121: 266-276.

Jackson R.B., Canadell J., Ehleringer J.R., Mooney H.A., Sala O.E. and Schulze E.D. 1996. A global analysis of root distribution for terrestrial biomes. Oecol. 108: 389-411.

James S.E., Meelis P., Wilson S.D. and Peltzer D.A. 2003. Temporal heterogeneity of soil moisture in grassland and forest. J. Ecol. 91: 234-239.

Johnson N.C., Tilman D. and Wedin D. 1992. Plant and soil controls on mycorrhizal fungal communities. Ecology 73 : 2034-2042.

Johnson N.C., Zak D.R., Tilman D. and Pfleger F.L. 1991. Dynamics of vesicular-arbuscular mycorrhizae during old field succession. Oecologia 86: 349-358.

Kling G.W., Hayhoe K., Johnson L.B., Magnuson J.J., Polasky S., Robinson S.K., Shuter B.J., Wander M.M., Wuebbles D.J., Zak D., Lindroth R.L., Moser S.C. and Wilson M.L.R. 2003. Confronting Climate Change in the Great Lakes Region; Impacts on our Communities and Ecosystems.
Union of Concerned Scientists, Cambridge, Massachusetts, and Ecological Society of America, Washington, DC.

Kloss S. and McBride J.R. 2002. Geographic variation in biomass production of California blue oak seedlings and water. USDA Forest Service General Technical Report PSW-GTR184.

Kochy M. and Wilson S.D. 2001. Nitrogen deposition and forest expansion in the northern Great Plains. J. Ecol. 89: 807-817.

Lawson D., Inouye R.S., Huntly N. and Carson W.P. 1999. Patterns of woody plant abundance, recruitment, mortality and growth in a 65 year chronosequence of old-fields. Plant Ecol. 145: 267-279.

McArthur E.D., Blauer A.C., Monsen S.B. and Sanderson S.C. 1995. Plant inventory, succession and reclamation alternatives on disturbed lands in Grand Teton National Park. In: Roundy B.A., McArthur E.D., Haley J.S. and Mann D.K. (eds), Proceedings: Wildland Shrub and Arid Land Restoration Symposium 1993, October 19-21, Las Vegas, NV, U.S. Department of Agriculture, Forest Service, Intermountain Research Station. General Technical Report INT-GTR-315, Ogden, UT, pp. 343-358.

McPherson G.R. 1997. Ecology and Management of North American Savannas. University of Tucson Press, Tucson, AZ.

Myster R.W. and McCarthy B.C. 1989. Effects of herbivory and competition on survival of Carya tomentosa (Juglandaceae) seedlings. Oikos 56: 145-148.

Packer A. and Clay K. 2000. Soil pathogens and spatial patterns of seedling mortality in a temperate tree. Nature 404: 278-281.

Peterson D.W. and Reich P.B. 2001. Prescribed fire in oak savanna: fire frequency effects on stand structure and dynamics. Ecol. Appl. 11: 914-927.

Rejmánek M. 1989. Invasibility of plant communities. In: Drake J., Mooney H.A., Di Castri F., Groves R.H., Kruger F.J., Rejmánek M. and Williamson M. (eds), Biological Invasions: a Global Perspective. Wiley, Chichester, pp. 369388.

Rice K.J., Gordon D.R., Hardison J.L. and Welker J.M. 1993. Phenotypic variation in seedlings of a "keystone" tree species (Quercus douglasii): the interactive effects of acorn source and competitive environment. Oecologia 96: 537-547.

Tilman D. 1987. Secondary succession and the pattern of plant dominance along experimental nitrogen gradients. Ecol. Monogr. 57: 189-214.

Tilman D. and Wedin D. 1991. Plant traits and resource reduction for five grasses growing on a nitrogen gradient. Ecology 72: 685-700.

Van Auken O.W. 2000. Shrub invasions of North American semiarid grasslands. Annu. Rev. Ecol. System. 31: 197-215.

Vitousek P.M., Walker L.R., Whiteaker L.D., Mueller-Dombois D. and Matson P.A. 1987. Biological invasion by Myrica faya alters ecosystem development in Hawaii. Science 238: 802-804.

Weltzin J., Archer S. and Heitschmidt R. 1997. Small-mammal regulation of vegetation structure in a temperate savanna. Ecology 78: 751-763.

Weste G. 1986. Vegetation changes associated with invasion by Phytophthora cinnamomi of defined plots in the Brisbane Ranges, Victoria, 1975-1985. Aust. J. Bot. 34: 633-648. 
Westover K.M., Kennedy A.C. and Kelley S.E. 1997. Patterns of rhizosphere microbial community structure associated with co-occurring plant species. J. Ecol. 85: 863-873.

Williams P.A. 1983. Secondary vegetation succession on the Port Hills Banks Peninsula, Canterbury, New Zealand. New Zealand J. Bot. 21: 237-247.

Williams P.A. 1992. Hakea salicifolia: biology and role in succession in Abel Tasman National Park, New Zealand. J. R. Soc. New Zealand 22: 1-18.

Wilson S.D. 1993. Belowground competition in forest and prairie. Oikos 68: 146-150.
Wilson S.D. 2000. Heterogeneity, diversity, and scale in plant communities. In: Hutchings M.J., John E.A. and Stewart A.J. (eds), Ecological Consequences of Habitat Heterogeneity. Blackwell Science, Oxford, pp. 53-69.

Wilson S.D. and Tilman D. 1991. Components of plant competition along an experimental gradient of nitrogen availability. Ecology 72: 1050-1065.

Wovcha D.S., Delaney B.C. and Nordquist G.E. 1995. Minnesota's St. Croix River Valley and Anoka Sandplain. University of Minnesota Press, Minneapolis, MN. 